\section{OBSERVATIONS ON TWO SONGS OF THE RUFOUS-SIDED TOWHEE}

A. JOHNS, 146-1128 McKercher Drive, Saskatoon

On July 18, 1977, my wife, Sandra, and I were taking a nature stroll in the Beaver Creek Park, a few miles south of Saskatoon. We were bird-watching and I was bird listening. About 1600 hours, we heard a Rufous-sided Towhee burst into song and I slowly approached the bird and made a 2minute recording of it. In order to entice the bird nearer and investigate its behaviour, I replayed the recording. The bird responded by coming closer and by increasing the vigour and frequency of its song.

We then left the bird in peace and went about our walk. One hour later I heard another song in the same general area of the first bird and, since this song was different, I recorded it. On noticing a Rufous-sided Towhee singing, we decided it was the same bird singing a different song. (This species has at least six different songphrases according to Peterson's A Field Guide to Western Bird Songs.) When I played the recording back to the bird, it approached us and began singing the second song with more vigour and more often.

I decided to wait a few minutes and play the first song (recorded an hour earlier) to the bird. This song was obviously recognized by the bird as a towhee song as it approached me again, singing its second song, vigourously and more frequently. I repeated this procedure from another position but, although I was playing the first song and the bird was responding to it, it would not revert to its first song.

EDITOR'S NOTE: A study of this species in Oregon found that an individual towhee had up to nine song types and that variations were identifiable within each type. D. E. Kroodsma. 1971. Condor 73:303308.

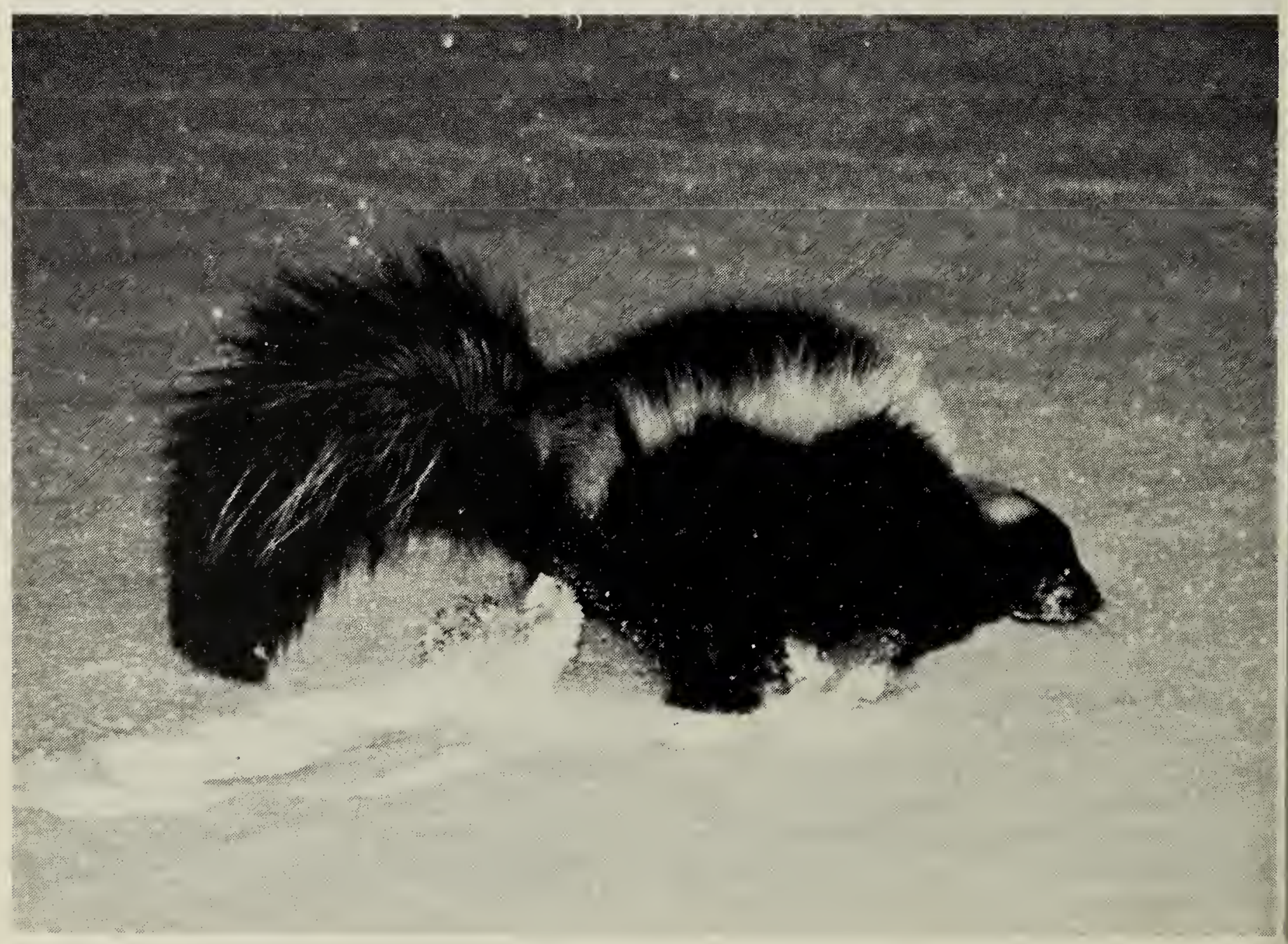

